\title{
Ultrasonic estimation of gestation age in goats via placentomes diameter Yaseen Mahmood Rasheed
}

Department of Surgery and Veterinary Obstetrics, College of Veterinary Medicine, Diyala

University, Iraq.

E-mail: dr.yaseen73@gmail.com

Received: 22/9/2015; Accepted: 22/12/2015

\section{Summary}

The aim of the present study is to establish the relationship between gestational age and placentome measurement via real-time ultrasound. This study is conducted in the college of Veterinary Medicine at Diyala University. Seventeen multiparous does were synchronized for estrus and naturally served to obtain pregnancy and subsequently scanned using both transducers. Ultrasonic (U.S) examination was performed transabdominally (TA) with sector-probe (5MHz) and transrectally (TR) with linear-probe $(7.5 \mathrm{MHz})$, in 10 day interval done started from day 35-135 post mating. The placentome was observed for the first time on day 35 by using TR ultrasonic examination $(7.5 \mathrm{MHz})$ linear transducer, as echogenic densities on the surface of endometrium. The results showed a significant increased $(\mathrm{P} \leq 0.05)$ in placentomes growth with gestation age. The placentome diameter (PD) reached maximized size around days $126(39.6 \pm 2.37 \mathrm{~mm})$. Also, the results indicated significant difference between placentome diameter (PD) size in single and twinpregnant does at $(\mathrm{P} \leq 0.05)$. The average of $\mathrm{PD}$ size in the single and twin-pregnant does was, respectively, $7.5 \pm 0.41 \mathrm{~mm}$ and $9.2 \pm 0.74 \mathrm{~mm}$ at the day 35 and 45 of gestation. The maximal size of PD was $39.2 \pm 2.50 \mathrm{~mm}$ in singleton-bearing does during $116-125$ day and $41.0 \pm 2.19 \mathrm{~mm}$ in twinbearing does during 126-135 day of gestation. In conclusion, the determination of gestation age according to placentome measurement was not reliable after day 90 . Also, the use of $7.5 \mathrm{MHz}$ linear array transducer for TR examination was found to be efficient, for early recognition of placentomes starting point from 35 days of gestation, as well as, the larger placentomes are expected in twinsbearing does.

Keywords: Ultrasound, Gestation age, Plcentomes, Goat.

Introduction

In most flocks of goats, natural breeding dates are generally unobserved or unrecorded, making fertile breeding impossible to determine. Furthermore, accurate information on the stage of gestation would be useful to monitor does near term (1). The early and precise detection of pregnancy in goat is especially important from economic point of view, the separation of the flock into pregnant and non-pregnant permits scheduling of the technology of breeding (2). Ultrasonography is a reliable technique for early pregnancy diagnosis would allow early culling or rebreeding of barren does (1 and 3). B-mode ultrasonography is an accurate, rapid and safe method for diagnosing pregnancy in small ruminants. Transrectal or transabdominal approaches could be used with nearly $100 \%$ accuracy rate (4-7). The size of fetal head (Biparietal diameter) and development fetal heart size between 40 and 100 day of gestation are reliable measures of gestation age (8). The other possible measurable objective variable included the size of placentomes, placentomes could be detected by trans-rectal ultrasono -graphy and $5 \mathrm{MHz}$ linear transducer at days 28-30 of gestation (9). The placentomes appear small echogenic areas on the surface of endometrium (10), later, they are readily imaged in cross section as cup-shaped hyperechogenic structures with the concave surface directed toward uterine lumen (4 and 5). The ultrasonography measurement of placentome during gestation offers an objective means of determining gestational age. Therefore, this study aimed to the relationship between gestational age and placentome measurement via trans-abdominal and trans-rectal ultrasonography in goats throughout pregnancy.

\section{Materials and Methods}

Seventeen multiparous does were employed in this study; their average age was 2-4 years. The study was conducted in the College of Veterinary Medicine-University of Diyala. 
The does had been synchronized for estrus by using the intra-vaginal sponges containing 20mg Cronolone (chronogest CR, Intervet, International B.V., Boxmeer, The Netherland) for 12 days. Applicator for insertion of chronogest $\mathrm{CR}$ vaginal sponge, at the moment of sponge removal, each doe received 400 I.U eCG (Folligon, Intervet, International B.V., Boxmeer, The Netherland), Intramuscularly. Estrus was carefully observed and every doe was naturally mated twice at the $1^{\text {st }}$ and $2^{\text {nd }}$ day of estrus, thus the first day of estrus was designated as day 0 of gestation. Ultrasono -graphic (U.S) examination was performed either trans-rectal or trans-abdominal using a real-time B-mode scanner (Welld ultrasound, Shenzhen well. D. Medical Electronics Co. LTD. China). Light wave record and play video, USB 2.0 TV BOX, ultrasound transmission gel. The transrectal examination was conducted with $5-7.5 \mathrm{MHz}$ linear array transducer, the transducer was fastened to a plastic rod $(30 \mathrm{~cm})$ length and $(20 \mathrm{~mm})$ in diameter and the examination done according to (11 and 12). Transabdominal examination was conducted with $3.5-5 \mathrm{MHz}$ convex array transducer and with $5-7.5 \mathrm{MHz}$ linear array transducer, the examination according to (4). U.S examination in 10 day interval start from day 35-135 post mating and the time spent on each animal to reach a diagnosis was always more than 2 min. estimates of gestational age (GA) in days depending in placentome diameter (PD) in millimeters was made according to the fallowing formula which clarified in (1) $\mathrm{GA}=28.74+1.80$ (PD), after 35 days of gestation .Also in current study, at three big sizes of placentomes was measured and then mean diameter of those placentomes were calculated. All measurements were in millimeters (mm). Least significant differenceLSD test was used to significant compare differences between different observations of each measurement in this study (13).

\section{Results and Discussion}

A total of 165 ultrasonographic examinations were obtained from seventeen does during 30-135 day of pregnancy. The data of (Table, 1) showed a significant effect $(\mathrm{P} \leq 0.05)$ in placentomes growth with gestation age. These results are in agreement with several previous researchers (1, 14 and 15) who revealed high correlation between PD and gestational period in small ruminants, moreover, in cattle (16). From (Table, 1) the placentome size was attained to overestimate gestation length around day 126 was $39.6 \pm$ $2.37 \mathrm{~mm}$. This observation was confirmed by (17 and 18) who found the placentome size was $4.08 \mathrm{~cm}, 2.58 \pm 0.33 \mathrm{~cm}$, respectively, in the identified period. From day 125 onwards it was cease growing of placentome in does (Fig. $1)$. These result close to (19). While in others studies (1, 20 and 21), which was carried out in ewes, the placentome diameter (PD) reached maximized size around days 90, 82 and 74 , respectively. Whereas, in sheep the placentomes cease growing around day 70 of gestation (1). The disparity between present study and previous due to differences in species of animal. The most restrictive factors of ultrasound are that its efficiency is always dependent on the expertise of the operator (22).

Table, 1: Ultrasonic measurement of placentome diameter at different Gestational age in goats.

\begin{tabular}{cc}
$\begin{array}{c}\text { Gestation Period } \\
\text { (days) }\end{array}$ & $\begin{array}{c}\text { Placentome size } \\
(\mathrm{mm})\end{array}$ \\
\hline $35-45$ & $\mathbf{8 . 3 5} \pm \mathbf{0 . 6 4}$ \\
$46-55$ & $\mathbf{1 2 . 3 5} \pm \mathbf{0 . 7 1}$ \\
$56-65$ & $\mathbf{1 8 . 5} \pm \mathbf{1 . 4 8}$ \\
$66-75$ & $\mathbf{2 5 . 2 5} \pm \mathbf{2 . 0 9}$ \\
$76-85$ & $27.7 \pm \mathbf{2 . 4 1}$ \\
$86-95$ & $\mathbf{3 1 . 1} \pm \mathbf{2 . 5 7}$ \\
$96-105$ & $33.2 \pm 1.98$ \\
$106-115$ & $39.5 \pm 2.82$ \\
$116-125$ & $39.1 \pm \mathbf{2 . 6 9}$ \\
$126-135$ & $39.6 \pm 2.37$ \\
LSD value & $\mathbf{8 . 9 2 4} *$ \\
& $*(\mathrm{P} \leq 0.05)$. \\
\hline
\end{tabular}

From the current study, the placentome was the most available structure of the pregnant uterus for ultrasonic examination and the placentome was easily observed for the first time on day 35 by using TR ultrasonic examination with $7.5 \mathrm{MHz}$ linear transducer, as an echogenic densities on the surface of endometrium (1, 2, 20, 21 and 23), (Fig. 2). 


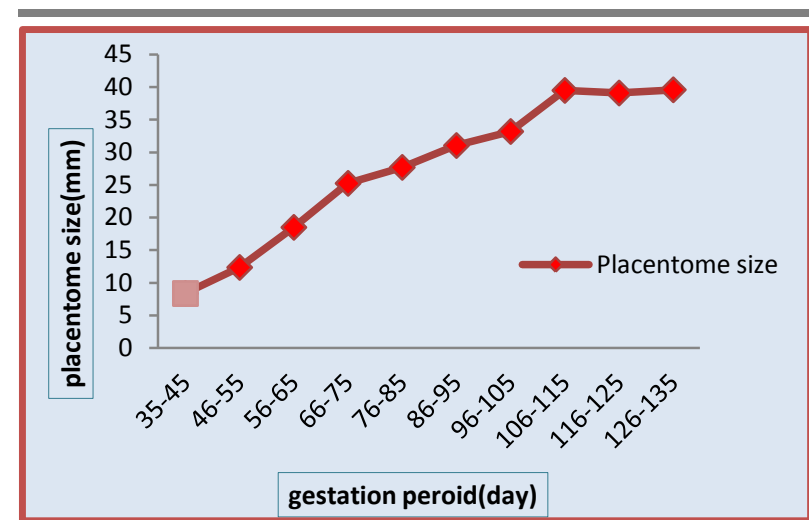

Figure, 1: Relationship between placentomes development and Gestation age in does.

At gestational age (35 day), the mean PD was $8.35 \pm 0.64 \mathrm{~mm}$ these result convergent with (11 and 18) who reported PD was $7 \pm 2$ $\mathrm{mm} ; 9.875 \pm 4.14 \mathrm{~mm}$, respectively. While (14 and 24) reported placentomes detected was on day 50 of gestation. The divergence between the results of present study and previous, might be attributed to use a TR ultrsono -graphic examination with $7.5 \mathrm{MHz}$ probe combined with improvement in resolution of the B-mode ultrasonic technology in this study, whereas, used TA ultrasonic scan with $5 \mathrm{MHz}$ transducer in previous study. Researchers (25 and 26) were reported the first time for placentome observed were around 25 day of gestation in ewes. Since the placentomes lies very close to the uterine wall, it might be prove difficult to find it especially for the first month of gestation, meanwhile, it projects from endometrium into the anechoic uterine lumen and could be identified it (12).

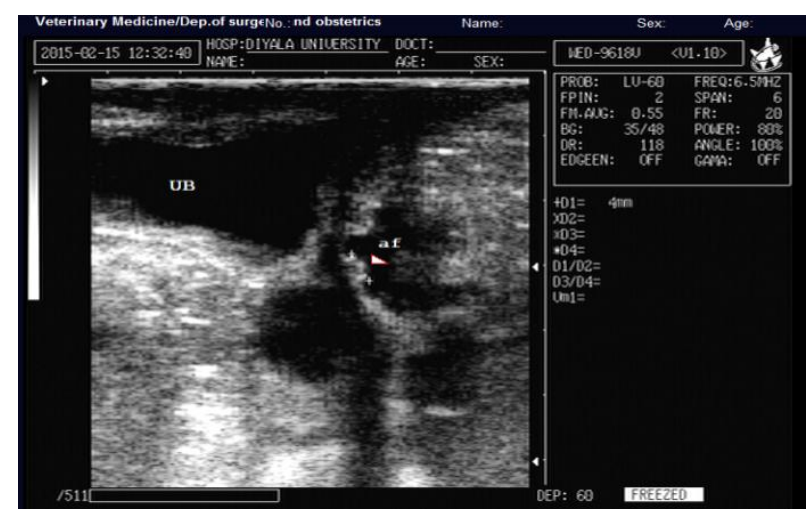

Figure, 2: Trans-rectal Ultrasonic images of 35day of pregnancy, Placentome: Arrowhead; u.b; urinary bladder; a.f: allantois fluid.

As pregnancy progressed, the placentome increase in size and appear as distinct $\mathrm{O}$ shaped and C-shaped echo densities surrounded by anechoic fluid when imaged in the longitudinal and cross-sectional planes, respectively (Fig. 3). This is almost similar to the registered by $(1,20$ and 27).
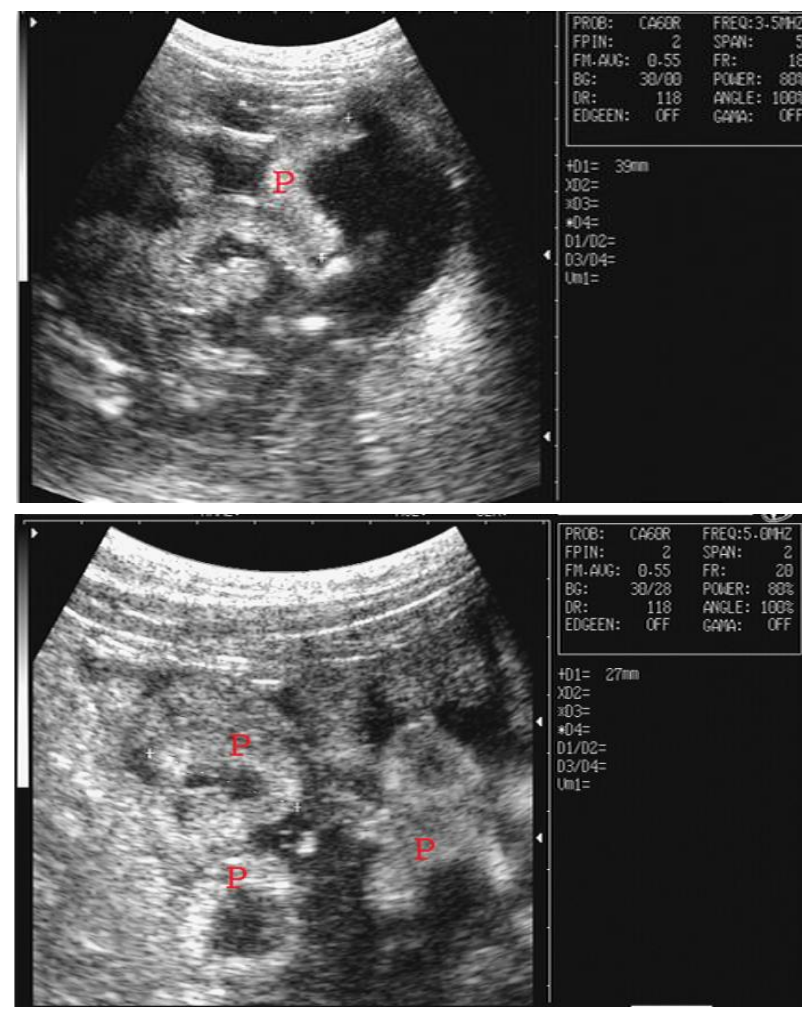

Figure, 3: Trans-abdominal Ultrasonic images of placentomes $(P)$ at gestational age 84 day in multiple-bearing (left image) and single-bearing doe (right image), using Sector probe.

Furthermore, the placentomes were measuring up to day 135 of pregnancy. These result was close to (24 and 28) whom reported that possible observed and measuring placentome in the last third trimester of pregnancy with $\mathrm{TA}$ approach and $5 \mathrm{MHz}$ sector probe. Meanwhile, these result disagreement with (1) who reported that it was difficult to visualized of placentome after about 100 day of gestation as well as not reliable for measuring by using TR ultrasonic examination with $5 \mathrm{MHz}$ transducer. This variation was explained by method of ultrasonographic scanning and probe frequency used in both studies. The results (Table, 2) shown there was significant effect $(\mathrm{P} \leq 0.05)$ in placentomes diameter between single and multiple pregnancy with progression of gestation in does, (Fig. 4 and 5). These observed coincided with result of (17) who explains that placentome size was variation according to number of fetuses during gestation period until twelve week of pregnancy (19). 

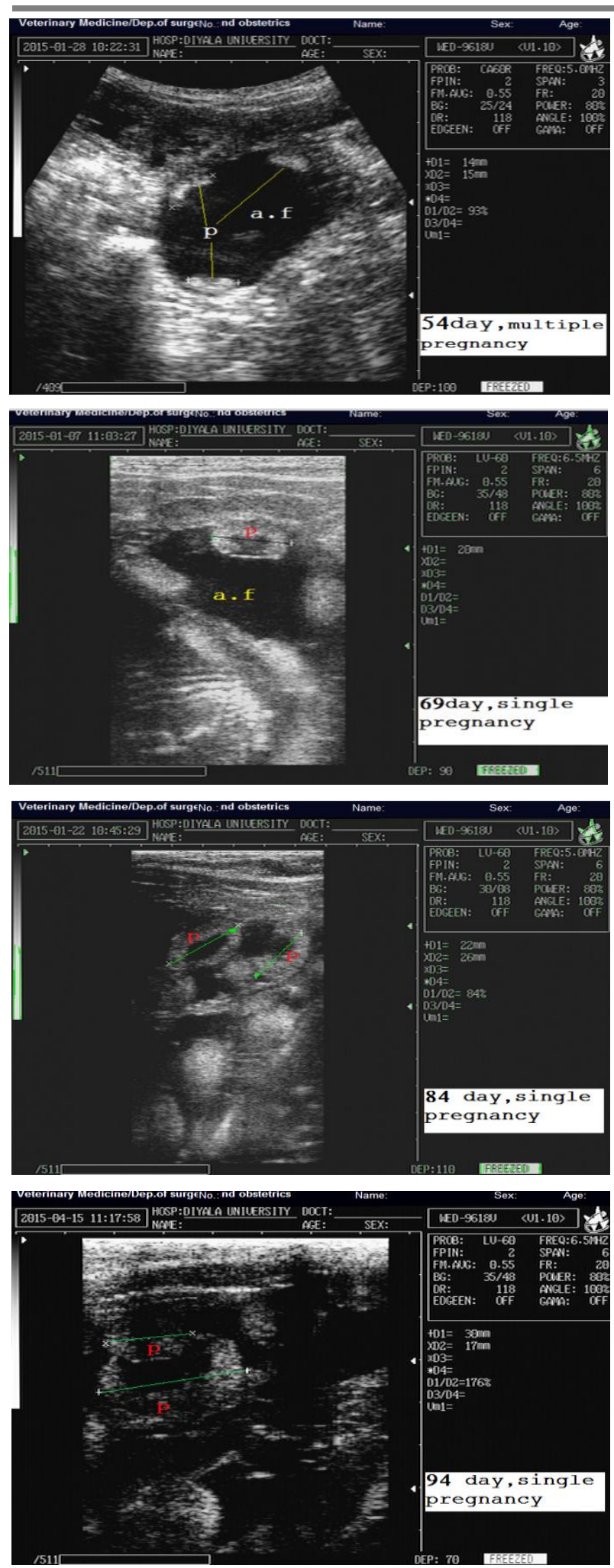

Figure, 4: Trans-abdominal ultrasonic images of PD in single pregnancy. $P$ : placentomes, a.f: Allantoic fluid. (Linear probe).

The mean values of PD are given in (Fig. $6)$, there was significant differences $(P \leq 0.05)$ in a rapid increase of PD were during 35-75 day and 35-105 day in singleton and multiplebearing does, respectively. These observed disagree with (26) was carry out on ewes, the differences between the studies might be attributed to the different of animal species. Moreover, there is no doubt that accuracy of the method in recognizing placentome is very high if the operator is adequately experienced (12).
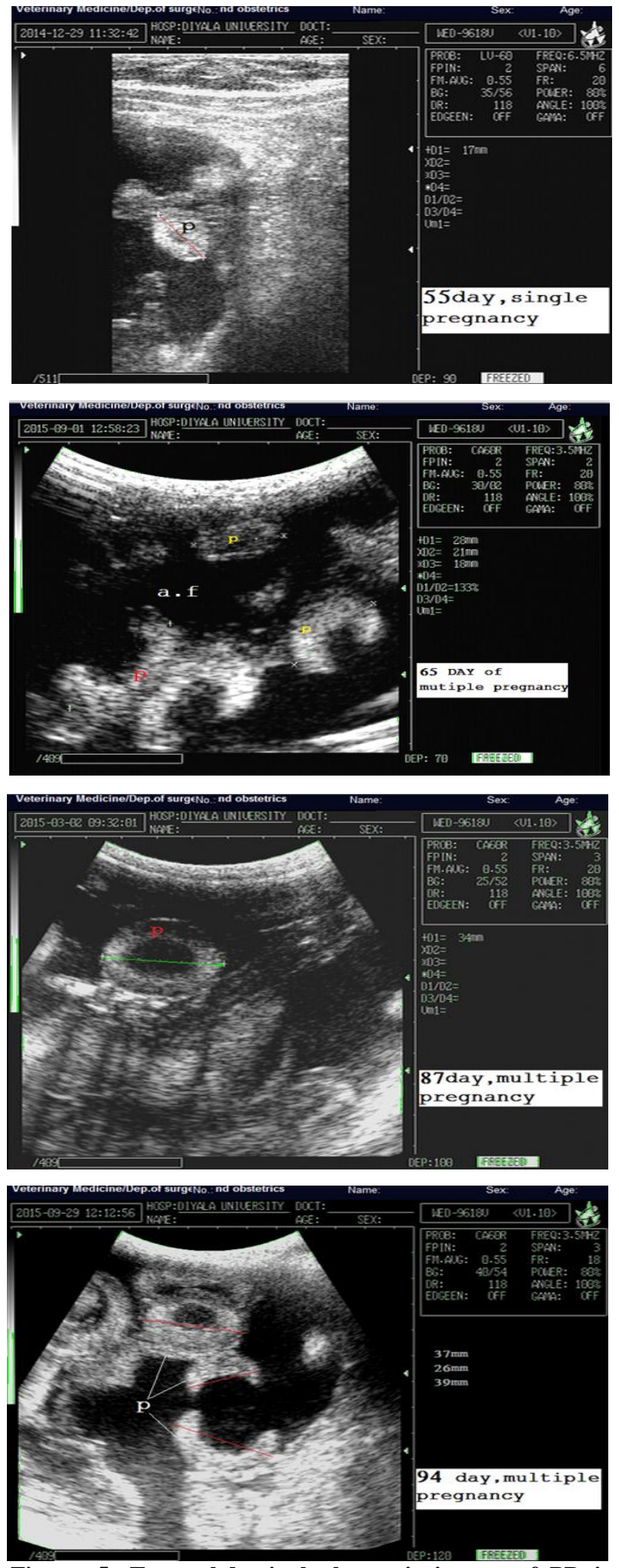

Figure, 5: Trans-abdominal ultrasonic images of $P D$ in multiple pregnancy. $P$ : placentomes, $a . f$ : Allantoic fluid. (Sector probe). 


\begin{tabular}{ccc}
\hline \multicolumn{3}{c}{ Table, 2: Comparison of placentomes diameter and } \\
gestational in single and Multiple-bearing goats. \\
\hline Gestation & \multicolumn{2}{c}{ Placentome size $(\mathrm{mm})$} \\
\hline $\begin{array}{c}\text { Period } \\
\text { (days) }\end{array}$ & $\begin{array}{c}\text { Single } \\
\text { Pregnancy }\end{array}$ & $\begin{array}{c}\text { Multiple } \\
\text { Pregnancy }\end{array}$ \\
$35-45$ & $\mathbf{7 . 5} \pm \mathbf{0 . 4 1}$ & $\mathbf{9 . 2} \pm \mathbf{0 . 7 4}$ \\
$46-55$ & $\mathbf{1 2 . 3} \pm \mathbf{0 . 8 5}$ & $\mathbf{1 2 . 4} \pm \mathbf{0 . 9 1}$ \\
$56-65$ & $16.5 \pm \mathbf{0 . 9 4}$ & $\mathbf{2 0 . 5} \pm \mathbf{0 . 7 6}$ \\
$66-75$ & $\mathbf{2 4 . 0} \pm \mathbf{1 . 2 6}$ & $\mathbf{2 6 . 5} \pm \mathbf{1 . 0 4}$ \\
$76-85$ & $\mathbf{2 5 . 4} \pm \mathbf{0 . 8 4}$ & $\mathbf{3 0} \pm \mathbf{2 . 5 7}$ \\
$86-95$ & $\mathbf{2 5 . 5} \pm \mathbf{0 . 9 1}$ & $\mathbf{3 6 . 6} \pm \mathbf{1 . 3 8}$ \\
$96-105$ & $\mathbf{2 6 . 0} \pm \mathbf{0 . 6 9}$ & $\mathbf{4 0 . 4} \pm \mathbf{1 . 2 5}$ \\
$106-115$ & $\mathbf{3 9 . 0} \pm \mathbf{2 . 3 9}$ & $\mathbf{4 0 . 0} \pm \mathbf{2 . 3 3}$ \\
$116-125$ & $\mathbf{3 9 . 2} \pm \mathbf{2 . 5 0}$ & $\mathbf{3 9 . 0} \pm \mathbf{2 . 6 4}$ \\
$126-135$ & $\mathbf{3 8 . 2} \pm \mathbf{2 . 4 4}$ & $\mathbf{4 1 . 0} \pm \mathbf{2 . 1 9}$ \\
LSD value & $\mathbf{7 . 9 3 9} *$ & $\mathbf{8 . 0 2 7} *$ \\
& $*(\mathrm{P} \leq 0.05)$. & \\
\hline
\end{tabular}

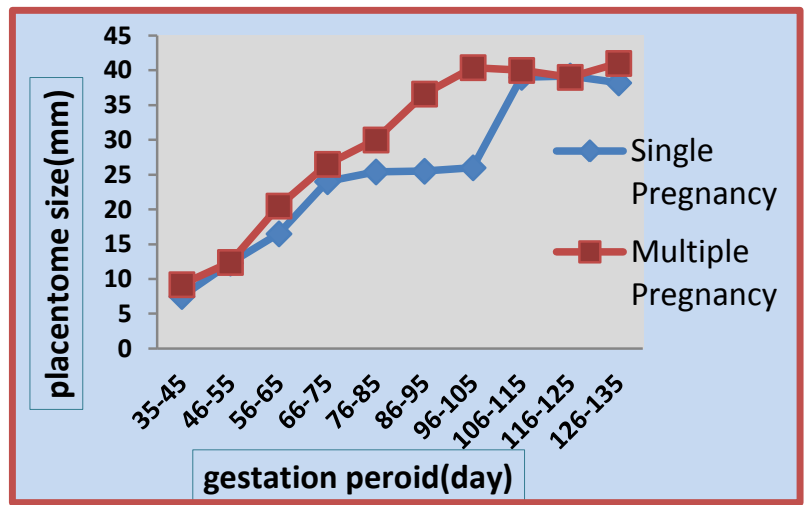

Figure, 6: Comparison of placentome size and gestational age in singleton and twin-bearing does.

The average of PD size in singleton and twin pregnant does was, respectively, $7.5 \pm 0.41$ $\mathrm{mm}$ and $9.2 \pm 0.74 \mathrm{~mm}$ at the day $35-45$ of gestation. Thus, larger placentomes are expected in twin's pregnancies (18). The maximal size of placentome was $39.2 \pm 2.50$ $\mathrm{mm}$ in singleton-bearing does in 116-125day and $41.0 \pm 2.19 \mathrm{~mm}$ in twin-bearing does during 126-135 day of pregnancy. These results are consistent with (26 and 29), but different from data of (1 and 30) were carry on sheep, the difference among the studies could be referring to animals species differences, equipment quality, transducer frequency, examination environment in addition to operator experience (12). In previous study, (23 and 31) whom concluded that PD increase more in twin pregnancy than in the singleton during the third month of gestation. This is in agreement with reported in present study. In conclusion, the determination of gestation age according to placentome measurement was not reliable after day 90, these observed was coincided to (1, 21 and 32) the authors reported that these $\mathrm{PD}$ is not helpful in prediction after third month (16).

\section{References}

1. Doize, F.; Vaillancourt, D.; Carabin, H. and Belanger, D. (1997). Determination of Gestation age in sheep and goats using transrectal ultrasonographic measurement of placentomes.Theriogenol., 48:449-460.

2. Yotov, S.; Dimitrov, M. and Vassilev, N. (2005). Early pregnancy diagnosis and examination of embryo-fetal growth in the local ovine breed. Bul. J. Agric. Sci., 11:119124.

3. Martinez, M. F.; Bosch, P. and Bosch, R. A. (1998). Determination of early pregnancy and embryonic growth in goats by transrectal ultrasound scanning. Theriogenol., 49(8): 1555-1565.

4. Haibel, G. K. (1990). Use of ultrasonography in reproductive management of sheep and goat herds.Vet. Clin. North Am., 6:597-613.

5. Bretzlaff, K.; Edwards, J.; Forrest, D. and Nuti, L. (1993). Ultrasonographic determina -tion of pregnancy in small ruminants. Vet. Med., 88:12-24.

6. Karen, A.; El Amiri, B.; Beckers, J. F.; Sulon, J.; Taverne, M. and Szenci, O. (2006). Comparison of accuracy of transabdominal ultrasonography,progesterone and pregnancyassociated glycoproteins tests for discrimina -tion between single and Multiple pregnancy in sheep. Theriogenol., 66:314-322.

7. Abdelghafar, R. M.; Bakhiet, A. O. and Ahmed, B. H. (2007). B-Mode real-time ultrasonography for pregnancy diagnosis and fetal number in Saanan goats. J. Anim.Vet. Adv., 6(5):702-705.

8. Raja, R. K.; Mohd-Nizam, A. R.; Abdullah, R. B. and Wan-Khadijah, W. E. (2011). Using fetal-heart size measured from ultrasound scanner images to estimate age of gestation in goat. J. Anim. Vet. Adv., 10(19):2528-2540.

9. Jenkinson, C. M.; Peterson, S. W.; Mackenzie, D. D. and McCutcheon, S. N. (1994). The effects of season on placental development and fetal growth. Anim. Prod., 54:227-230. 
10. Buckrell, B. C. (1988). Application of ultrasonography in reproduction in sheep and goats. Theriogenol., 29:71-83.

11. Mohmamed, M.; Gen, W.; Gamal, A.; Kazuaki, S.; Sayed, S. and Kazuyoshi, T. (2004). Early pregnancy diagnosis by means of ultrasonography as a method of improving reproduvtive efficiency in goats. J. Reprod. Dev., 50(4):391-397.

12. Gonzalez-Bulnes, A.; Pallares, P. and Vazquez, M. I. (2010). Ultrasonographic Imaging in Small Ruminant Reproduction. Reprod. Dom. Anim., 45(2):9-20.

13. SAS. (2012). Statistical Analysis System, User's Guide. Statistical. Version 9.1 ${ }^{\text {th }}$ Ed. SAS. Inst. Inc. Cary. N.C. USA.

14. Suguna, K.; Mehrotra, S.; Agarwal, S. K.; Hoque, M.; Singh, S. K.; Shanker, U and Sarath, T. (2008). Early pregnancy diagnosis and embryonic and fetal development using real time B-mode ultrasound in goats. Small Rumin. Res., 80(1):80-86.

15. Karen, A. M., Fattouh, E. M. and Abu-Zeid, S. S. (2009). Estimation of gestational age in Egyptian goats by ultrasonographic fetometry Anim. Reprod. Sci., 114:167-174.

16. Adeyinka, F. D.; Laven, R. A.; Lawrence, K. E.; Van Den Bosch, M.; Blankenvoorde, G. and Parkinson, T. J. (2014). Association between placentome sizes measured using transrectal ultrasonography, and gestational age in cattle. N Z Vet. J., 62(2):51-56.

17. Yougwon, L.; Okken, L.; Jongki, C.; Hyunguk, S.; Yoonsuk, C.; Yonghee, S.; Wonil, C.; Heejae, S.; Doosoo, L.; Gwansum, L. and Sangtae, S.(2005). Ultrasonic measurement of fetal parameters for estimation of gestational age in Korean black goats, J. Vet. Sci., 67(5):497-502.

18. Roukbi, M. (2013). The use of ultrasonography for early detection of pregnancy and measurement of some foetal pattern in Damascus goats. Iraqi J. Vet. Med., 27(1):35-44.

19. Hradecky, P.; Mossman, H. W. and Stott, G. G. (1988). Comparative development of ruminant placentomes. Theriogenol., 29(3): 715-729.

20. Ali, A. and Hayder, M. (2007). Ultrasono -graphic assessment of embryonic, fetal and placental development in Ossimi sheep. Small Rum. Res., 73:277-282.
21. Metodiev, N.; Dimov, D.; Ralchev, I. and Raicheva, E. (2012). Measurements of fetal growth via transabdominal ultrasonography during first half of pregnancy at ewes from synthetic population Bulgarian milk. Bulgarian J. Agricul. Sci., 18(4):493-500.

22. Gayrard, V.; Carriere, P. D.; and Descoteaux, L. (2010). Principles and recommendations, essential concepts, and common artifacts in ultrasound imaging. In: Practical atlas of ruminant and camelid reproductive ultrasono -graphy. Coteaux, L.D.; Colloton, J. and Gnemmi, G. (Ed.).Wiley-Blackwell. Pp:3-19.

23. Kaulfuss, K. H.; Uhlich, K. and Gille, U. (1998). Ultrasonographis examination of the placentoma development in pregnant sheep. Dtsch Tierarzti Wochenschr, 105(4):162-167.

24. Raja-Khalif, R. I. A. Rahman, M. M. WanKhadijah, W. E. and Abdullah, R. B. (2014). Pregnancy diagnosis in goats by using two different ultrasound probes. J. Anim. Plant Sci., 24(4):1026-1031.

25. AL-Rawi, H. M.; Omran, S. N. and Hussein, K. A. (2007). Estimation of fetal age in sheep by measurement of transthoracic, trans abdominal, cotyledon length and width by using real-time ultrasonography. Iraqi J. Vet. Med., 53(4):122-132.

26. Kasikci, G.; Turna yilmaz, O.; Can Gnnduz, M. and Kirsan, I. (2011). Comparison of placentome diameters in single and twinpregnant sheep by ultrasonographic method. Turk. J. Vet. Anim. Sci., 35(3): 187-191.

27. Gardner, D. S.; Ward, J. W.; Giussani, D. A. and Fowden, A. L. (2002). The effect of a reversible period of adverse intrauterine conditions during late gestation on fetal and placental weight and placentome distribution in sheep. Placenta, 23(6):459-466.

28. Zongo, M.; Traoré, I.; Pitala, W.; Boly, H.; Sanou, D.; Belemtougri, R. and Sawadogo, L.( 2014). Estimation of fetal weight using ultrasonic measurements of fetal parameters in West Africa Sahelian goats. Can. J. Anim. Sci., 94:437-443.

29. Grace, N. D.; Beach, A. D.; Quinlivan, T. D. and Ward, B. (1989). Multiple pregnancy diagnosis of using real-time ultrasonic body scanner and video-flouroscopy systems. N. Z. Soc. Anim. Prod.; 49:107-111.

30. Aydın, İ.; Celik, H. A.; Şendag, S. and Dinç, D. A. (2008). Determination of placentome 
development and gestational age by ultrasono -graphic measurements in ewes. Vet. Bil. Derg., 24:29-34.

31. Al-Fatlawy, H. J. (2015). A comparison of gravid uterine parameters of local breed ewes between single and twin pregnancies in different gestational stages. AL-Qadisiya J. Vet. Med. Sci., 14(1):61-64.

32. Nwaogul, I. C.; Anya, K. O. and Agada, P. C. (2010). Estimation of foetal age using ultrasonic measurements of different foetal parameters in red Sokoto goats (Capra hircus). Vet. Arhiv., 80(2):225-233.

$$
\begin{aligned}
& \text { استعمال الموجات فوت الصوثية في ثقدير الحمل في المعزعن طريق قياس قطر القلقات الرحمية } \\
& \text { ياسين محمود رشيد }
\end{aligned}
$$

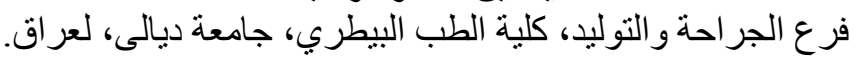

E-mail: dr.yaseen73@gmail.com

هدفت الدراسة الحالية إلى تقدير مدة الحمل بقياس قطر الفلقة الرحمية عند مراحل الحمل المختلفة في المعز باستعمال

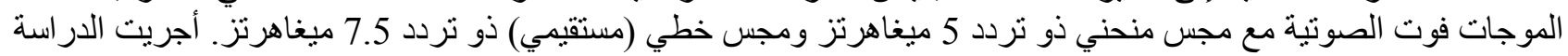

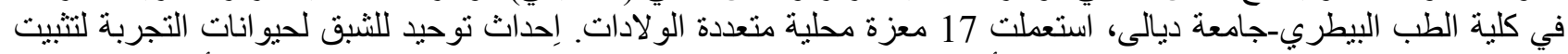

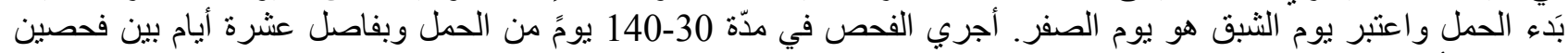

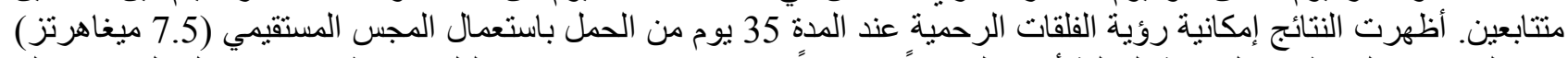

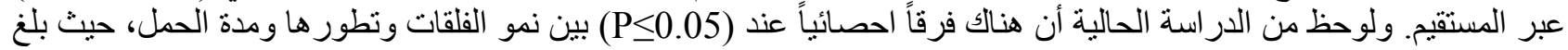

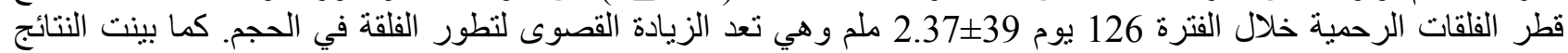

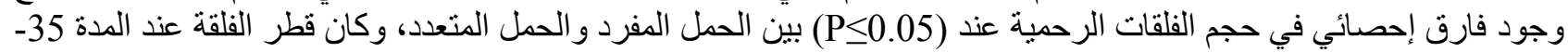

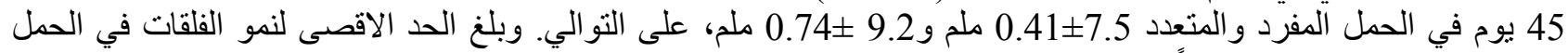

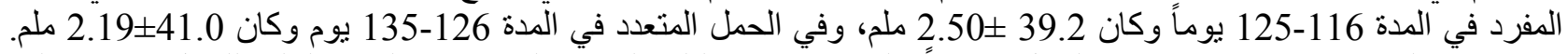

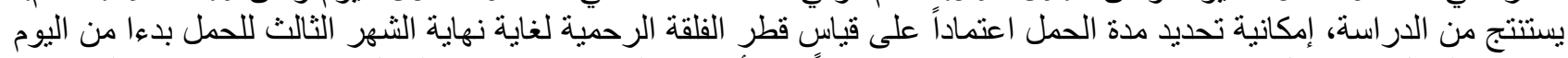

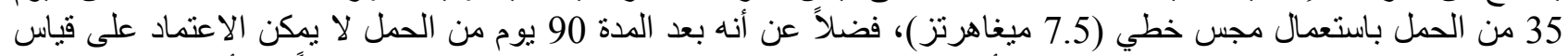

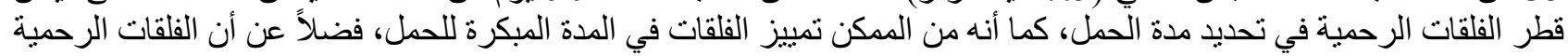

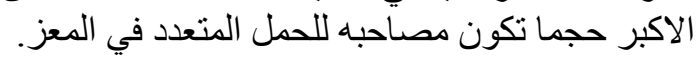

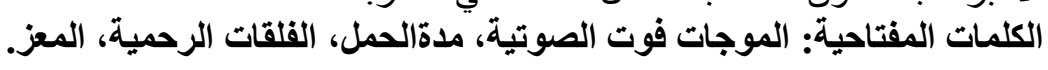

